\title{
New Trends in Port Community Systems and Fundamental Descriptions
}

\author{
Ekaterini Sfiroera \\ Dept. of Industrial Design \\ and Production \\ Engineering \\ University of West Attica, \\ Athens, Greece
}

\author{
C. Alafodimos \\ Dept. of Industrial Design \\ and Production \\ Engineering \\ University of West Attica, \\ Athens, Greece
}

\author{
M. Papoutsidakis \\ Dept. of Industrial Design \\ and Production \\ Engineering \\ University of West Attica, \\ Athens, Greece
}

\author{
D. Papachristos \\ Dept. of Industrial Design \\ and Production \\ Engineering \\ University of West Attica, \\ Athens, Greece
}

\begin{abstract}
This paper aims to present the Port Community Systems (PCS), their functions, their architecture and the significant role they play in the competitiveness of ports resulting from their use, through their applicati8on with data obtained from the international literature. It mainly focuses on the ports of the Mediterranean and the Adriatic area from the perspective of the strategic position they hold though the application of MED-PCS and APC project. This paper also, aims to focus on the necessity of measuring the performance of ports in order to determine the objectives and aims at ports' activity, and over their competitors (other ports).
\end{abstract}

\section{Keywords}

Port Community Systems (PCS), Key Performance Indicators (KPI), Mediterranean Ports, Greek Ports, Single Window

\section{INTRODUCTION}

As long as humanity has used water as a mean of transport, ports have served a crucial purpose, allowing the transport of goods and people from the water on earth. Also is given to ports, as hubs for freight flows, the significant and long-term role in the flow of information. The ever increasing demands on volume, speed, cost, quality and safety of people and goods movement makes it more meaningful than ever to modernize and optimize any type of port operation in order to meet modern needs.

Nowadays, this is starting to be established by automated and integrated information systems, which actually assume the role of "coordinator" of the basic functions of ports and interconnected transport, ensuring quick and safe movement of people and goods. The use of electronic data exchange and automation of all types of processes involved in freight and passenger traffic in ports are key- points to the modernization of ports since all these processes can be monitored, recorded, controlled and coordinated through integrated and automated information systems. The most innovative trends regarding the modernization of port procedures include the development and implementation of electronic communication ports with Common (or Global) Single Window Platforms, which contribute to communication among stakeholders that work in the port and between the interconnected ports, developing cooperative and competitive networks in order to save time, optimize procedures, speed up and coordinate many processes, save energy, reduce the environmental burden and ensuring the security of transport.

Such informational communication platforms have already begun to develop and operate both within the ports and across many interconnected ports worldwide making them integral parts of port networks, which operate, collaborate and compete within the framework and rules, to ensure a healthy and modern environment for the modernization and development, environmental protection, promotion of new business operations and for the attraction of financial capitals.

\section{PORT COMMUNITY SYSTEMS}

Using electronic data exchange, the PCS is an effective information system that serves in real time the fast, focused, flexible and versatile, stages of port processes in order to improve efficiency through fast loading, unloading procedures, customs clearance and transfer into and out of the terminals. Besides the above, PCS offer improved safety, reduced costs and possibly achieves greater competitiveness for each user.

The Information Port community systems (PCS) are defined as neutrals and open electronic platforms enabling secure information exchange between public and private stakeholders to improve the competitive position of the port community [1]. They are developed from port users and implemented by them and are recognized as the most advanced method for exchanging information within a port infrastructure. They are also easy, quick and efficient data exchange (EDI) available continuously throughout the year.

They are aimed at all port procedures and include all relevant companies, enterprises and organizations governing the port community. The parties involved are the current users of the port community systems in the literature, referred also as managers of information community systems [2].

\subsection{Port Community Systems and Competitive Advantage}

Competitive advantage can be achieved through Port Community Systems using modern and high performing features, being able to react to the five competitive forces as described by Michael Porter.

Porter's competitive model argues that much of a business's success or failure depends on its ability to respond to its external environment, comprised of competitors, substitute products, customers, suppliers new entrants and new markets [3]

A port is considered competitive when all the functions and services it provides are made to save time and operational costs while optimizing the reliability, security and quality of the services provided. All of these goals can therefore be achieved by utilizing the electronic services provided by integrated IT applications. Such applications tend to become more important especially in the case of neighboring ports, where the basic competitive differentiation depends on the total transport cost to be paid by the customer as well as the 
quality and speed of handling of the port services [4]. In the context of port marketing and port competition, following the market analysis and SWOT analysis of port services, the objectives for services are set and the strategies to achieve these objectives are identified. These objectives mainly concern services and port pricing policy.

\subsection{Stages of Implementation of a Port Community Information System}

The need for development of Port Community Systems is imperative and is proposed as a solution to eliminate ports' deficiencies and inefficiencies as ports are obvious congestion places to international trade and transport as international trade development has revealed several inefficiencies and shortcomings in ports' business processes as well as delays in the movement of goods through ports.

The process aimed at defining the functional and technical requirements of the online platform to be used jointly by members of the port community is a fundamental process for implementing such a system.

Good cooperation with all interested parties, potential users and stakeholders and organizations is crucial for the proper planning of a PCS and it is also noted that for the proper functioning of such a system is important to implement special training seminars tailored to needs and requirements of the users of ports.

Port community information systems (PCS) tend to automate existing processes with long-term or potential targets to discover the most optimal port operation. Their development is from a non-existent or limited existing system through its deployment to a workable community system and then a PCS for exploratory purposes through the evolution of the information system's architecture, assuming that its design system is only part of the full development process.

Choosing the right architecture is in line with the evolutionary stage and objectives of the development of the port community's information systems (PCS) and it is very important for the success of the system. The requirements are defined by a working group, involving all the partners. This group draws up a final document, which outlines the main technical requirements of the platform, and identifies ways to meet the needs of potential users and the market objectives to be achieved. This document is submitted to the interested parties for final approval. [5].

In studies of PCS systems in their application around the world, it is clear that tests in their development are not unique to each geographical area. In many cases, the success or failure of system implementation was re-examined and was due to specific issues raised during the distinct stages of system development.

Design process and PCS application can be roughly divided into four phases:

the start of the project,system analysis and design, implementation and adoption by the operators, maintenance and development of the system.

At the start of the project, stakeholders should be identified and involved in the formulation of the underlying problems and should also define the objectives and scope of the project. Also, during the start-up phase, all parties need to understand the costs that others (including government agencies) will bear. At this stage, potential problems arise both in the formation of the information system and in sponsorship.
In the system analysis and design stage, the system requirements based and configured according to the business context are transformed into a standard information system. This model serves as the basis for designing the information system architecture and choosing the language and form of communication. The architecture of the system should reflect the organizational context.

A system that reflects the current business environment will look less like a radical change and more like an automation or technology facility.

Type I Port Community Information Systems, are almost exclusively for the purpose of simple messaging without any smart supportive functional implementation. The next generation of port systems, called Type II, have been envisioned as key node systems with intelligent decision support functionality [6]

PCS Type II offer more possibilities for data integration and flexibility in offering new services and communication channels. The architecture of the former Information Systems (PCS type I) has a more complex structure, leading to higher maintenance costs and experiencing difficulties in expanding with new services and communication channels. Therefore, the transition from Type I to Type II does not happen easily or quickly, especially in view of the conservative attitude towards change in the shipping community of the supply chain and logistics services.

The implementation of the information system is the stage where an organization changes its business practices and applications in order to interconnect with the information system. In a network of organizations, the decision taken by each organization to actively start using the information system is the process of adopting the system.

The primary lesson from this stage of development is that it is a strategic implementation that will most likely help to develop the organization.

Since port community information systems are often big and designed to connect a network of partners, at this stage we may see confusion between the business as a unit and the network. Lack of enterprise-level resources could lead to the withdrawal of an organization from implementation. This in turn can have a direct negative impact on the benefits of all other network participants. Implementation of the system should therefore be properly addressed to ensure continued interest and support for all parties involved.

One method to achieve this is through an implementation strategy in which each unit has clear objectives and will quickly realize the benefits to all parties involved.

The development of a port community system is not a time period fact but a continuous process. In order to synchronize system specifications with customer requirements, continuous change is required, to maintain high system usage levels. The flexibility to evolve is the main activity that we need as we have learned from this stage of development. The ability of the information system to evolve in order to seize emerging opportunities allows the success of the system to continue.

However, due to continual change, both inside and outside the parties involved within the port community, loopholes occur between participants and technology.

In addition, the factors that originally influenced approval and implementation are expected to change. In the harbor, port community systems tend to follow the documented stages of 
information technology, by redesigning the automated existing processes into process redesign [7]

In general, information technologies are applied to commercial flows from two radically different perspectives: exploitation and exploration.

Exploitation refers to a category of actions undertaken to improve operational efficiency while exploration refers to a category of actions undertaken to discover new possibilities. At present, most port community information systems (PCS) emphasize on automation and integration of information flows from different parties in order to normalize or improve the physical flow of goods.

\subsection{Port Community Systems and Logistics Services}

In general, information technologies are applied to commercial flows from two radically different perspectives: exploitation and exploration.

Exploitation refers to a category of actions undertaken to improve operational efficiency while exploration refers to a category of actions undertaken to discover new possibilities. At present, most port community information systems (PCS) emphasize on automation and integration of information flows from different parties in order to normalize or improve the physical flow of goods.

The functions of the already developed port community platform systems cover areas such as: logistics services, customs clearance services, declaration of dangerous goods, and navigation services.

The logistics function requires the provision of electronic communications for the efficient management of the entire supply chain, from the inland transport to maritime transport, without compromising the private nature of commercially sensitive data. Customs clearance simplifies import and export control procedures and offers better control over the administrative process. This procedure reduces customs clearance times and provides easy access to information. Better functionality of the goods declaration is made through the use of electronic communication to ensure the efficient flow of data for the declaration of the transport of dangerous goods and the related obligations related to their management. PCS navigation services also guarantee an effective approach to smooth and safe traffic and optimal design on arrival and departure. It typically includes requests for services, execution and administration [8]

To promote and enhance logistics services at ports in order to make ports more efficient with the ultimate goal of delivering freight faster, more accurately and with less cost logistics, services should be developed in:

Managing and storing loads, Shipping, distribution and value added services and appropriate investments in machinery and information systems to make the above activities more efficient.

\subsection{Existing Port Community Systems in the Mediterranean Region}

The reasons for focusing on the Mediterranean are many but the most important one is that it has a strategic geographic location that makes it one of the most preferred transhipment areas in the world as it is one of the main shipping routes from Southeast Asia to Northern Europe and the west coast of America.
Statistically, container traffic on the Asia-Europe route has been estimated at 20.3 million TEUs in 2011, with 14.1 million TEUs in the foot from Asia to Europe and 6.2 million TEUs in the opposite direction. [9]

Several efforts have been made to integrate Mediterranean ports into a single electronic management system that will provide them with the port community information system they will manage. The most significant of these efforts are through the MED-PCS project for the Mediterranean ports and through the APC project for the Adriatic Port Community.

\subsubsection{MED-PCS}

The Med Ports Community is a platform consisting of the ports of Tarragona, Baleares, Cartagena, Salerno, Bastia, Sète, Livorno and Toulon. This port group seeks to promote cooperation between Spain, France and Italy and promote cooperation between the public and private sectors. MED-PCS's main objectives is the development of cabotage between the countries of the European Union.

This is expected to be achieved through the following actions:

Promote cooperation between the public and private sectors in order to design and propose joint solutions that will lead to improvements both in regulations and in any other matter related to shipping

$\square$ providing a description of the current shipping situation in the Mediterranean region in order to recognize the prospects and on this basis to identify possible realistic development alternatives

Promote the exchange of views between the Mediterranean region on the state of shipping, recognizing the prospects and identify the development of alternatives

Promote the exchange of views within the Mediterranean area on the state of maritime shipping in general and on short sea shipping in the Mediterranean

$\square$ Help improve understanding between Spain, France and Italy and other Mediterranean countries to cooperate at national and European level

$\square$ Analyze the situation of Mediterranean shipping in the rest of the European Union

$\square$ organizing conferences, symposia or other meetings on specific topics for the purpose of their analysis or subsequent publication,

1] integrating transport nodes with an effective way of analyzing the corresponding with each other in order to be able to include combined or intermodal transport in the goods distribution process

Making recommendations for improvement in relation to shipping, both from perspective to intermodal transport and exclusively for the port

$\square$ protecting the interests of other players in shipping industry

developing studies and participating in projects within a European framework and, where appropriate, in national projects

$\square$ organizing events, special symposiums, visits, and other things related to their social work

$\square$ promoting and enhancing their private collaboration in national and European programs. As they have achieved a 
close cooperation with all actors involved in the transport chain in order to gain a more complete picture of intermodal transport chains.

$\square$ providing maritime information, publicity and visibility in its fullest, as well as the form of short sea shipping in the Mediterranean region. [9]

The MED-PCS consists of 7 Project Partners, coming from 3 different Mediterranean countries (Spain, Italy and Greece).
This project contributes to the development and implementation of new functions in the existing Port Community Systems (PCS) of four Mediterranean ports: Tarragona (Spain), Cartagena (Spain), Bari (Italy) and Igoumenitsa (Hellas).

Through the MED-PCS project, these four ports link their Information Systems to each other and enhance the supply chain's efficiency in order to improve their competitiveness.

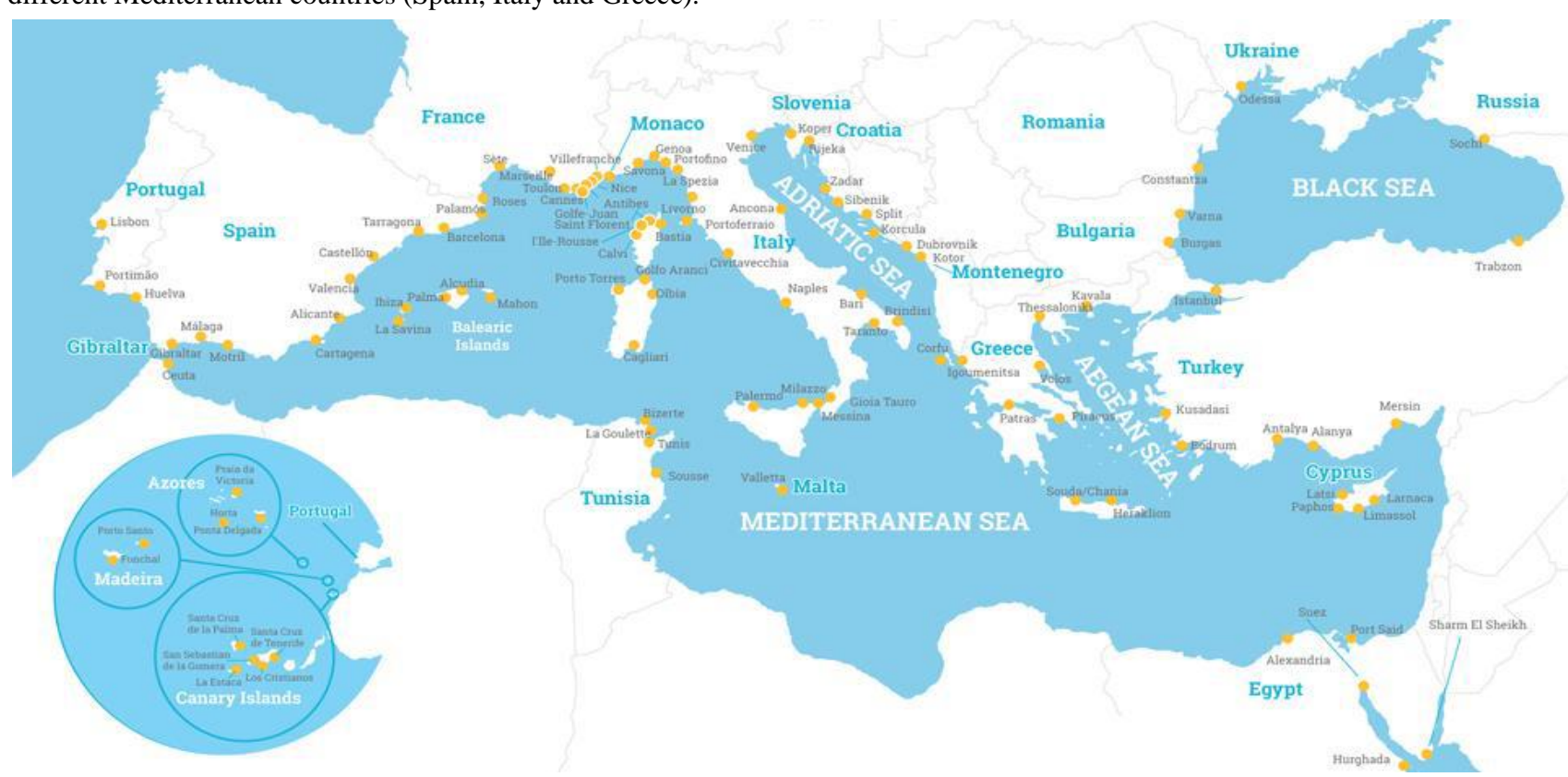

Fig 1: Ports of Mediterranean [15]

\subsubsection{Adriatic-PCS}

The Adriatic Port Community (APC) project aims at developing a modern information exchange information system for the ports involved in the initiative, namely Venice (Italy), Igoumenitsa (Greece) and Ploce (Croatia).

This system will be based on the Single-Window principle and will enhance the exchange of information gathered through different IT systems developed by each partner.

With this modern IT system, the APC Project aims to:

$\square$ modernize the administrative procedures related to the arrival and departure of ships, in particular in terms of time,

help to manage the flow of goods and improve management of parking areas within port areas, and eventually improving the efficiency and competitiveness of the three ports involved in the Project [5]

APC ports have developed the "Single Window" service to exchange useful information between local PCS. One aspect of the project that is challenging is that the above-mentioned ports have different characteristics as well as a degree of application of technology and information.

The experience of the continued development of PCS in three Adriatic ports (Venice, Italy, Ploče in Croatia and Igoumenitsa in Greece) has revealed a number of obstacles that require effort and time to overcome, namely the lack of integration of information systems and customs operations, the extraction of useful information from databases and the difficulties of restructuring some port operations. [11]

\section{KEY PERFORMANCE INDICATORS} (KPI)

The port must assess how effective and efficient its operations are, in order to compare current performance with this of the past, to set objectives and targets in port activity level, and over its competitors (other ports). As a performance metric, means of quantization process efficiency and effectiveness of an operation, the performance metric is a great help in the formation of seizures and decision making. [10]

Performance indicators quantify and simplify information about those decision makers and other stakeholders to assess whether activities and operations affecting the direction and size change in terms of socio-economic, governance and environmental conditions.

The proposed port performance indicators must be divided into two main categories:

Economic: they quantify port impact on economic activity Operational: that evaluate the measurements to input / output ratio of port operations in relation to the measures of port productivity and efficiency.

Performance indicators should also be readily available, realistic, easily measurable, strategically relevant and customer-oriented [13]

To be meaningful and useful KPI should be observable, quantifiable, sensitive to changes (to be able to indicate improvement / deterioration), compatible (not unlike other indicators KPI), easily understood and resistant on the manipulation of data from third parties [14] 
Key performance indicators (KPI) must also comply with some basic requirements:

Measurements should not be too detailed, and should, as far as possible, be based on measurements which have already been accepted. They must be limited in number (5-10) since a larger number will distract and give less significance to the measurement and if it is necessary, a set of multiple performance indicators can be merged to create a default index KPI. Also Key performance ratios (KPI) should be mutually exclusive, to ensure that the fullness of the possibilities are covered [14]

According to the international literature most important performance indicators for Freight Transport Activities are: 1.Financial, 2. Economic, 3. Operational/Human resources, 4. Customs Procedures, 5. Sustainability / Security.

The performance indicators are difficult to use for comparing different areas and ports so they should be defined for each port separately and individually but again benchmarking is necessary [13].

Many organizations measure the performance, especially in private sector. They may do it systematically and extensively or occasionally and superficially, nonetheless they do it. Performance measurement is an important aid in the formation of crisis and decision.

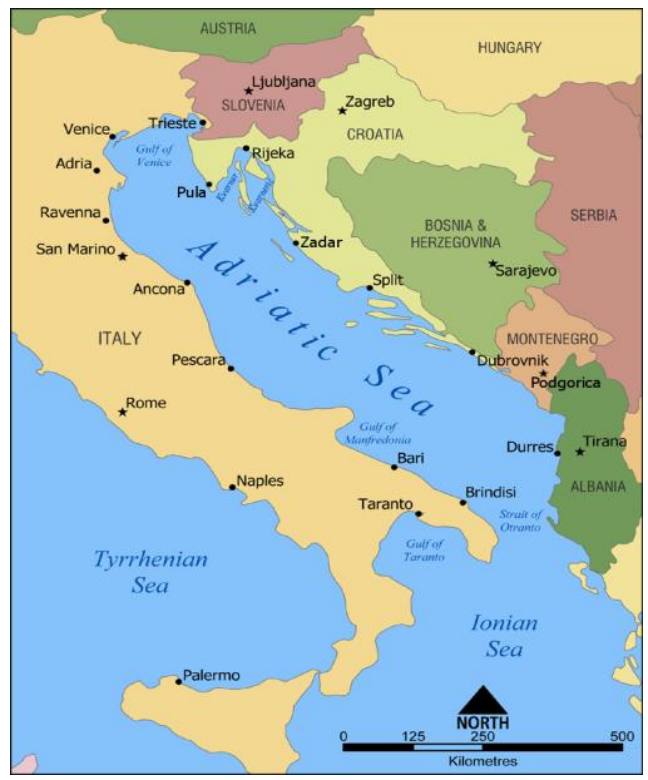

Fig 2: Adriatic Sea Region [16]

The APC project - The Adriatic Port Community aims at developing a modern information exchange information system for the ports involved in the initiative, namely Venice (Italy), Igoumenitsa (Greece) and Ploce (Croatia).

This system will be based on the Single-Window Principle principle and will enhance the exchange of information gathered through different IT systems developed or developed by each partner.

With this modern IT system, the APC Project aims to:

$\square$ modernize the administrative procedures related to the arrival and departure of ships, in particular in terms of time,

$\square$ help to manage the flow of goods and improve it management of parking areas within port areas, eventually improving the efficiency and competitiveness of the three ports involved in the Project [5].

\section{CONCLUSION}

Maritime transport must immediately be upgraded due to very intense modern competitive environment this can be achieved with the application and use of modern and innovative technologies for monitoring, control, automation and simplification of all processes of a port and with the promotion of communication, direct information exchange and synchronization of all the interconnected ports to act as port networks at local, national and international level.

The development of port networks leads to the proper and smooth functioning and enhance their competitiveness, following common rules and policies in relation to their individual processes.

Overall, the ports that offer such systems are easier to use and, therefore, more attractive to existing and potential users.

A basic prerequisite for the development of such port community systems is a sense of "community".

Also it's important that all members of the port community agree that they have common interests and accept a joint action plan for achieving the required development of such systems

As mentioned above the measurement and comparison of the key performance indicators (KPI), are useful for obtaining a full image of the port in order to provide improvements or changes to achieve the optimum performance. Regardless of the difficulties that may arise, the widely recognized advantages of Port community systems to harmonize and standardize operations, reduce bureaucracy, saving time and develop to an errorless environment, enhance the transformation of conventional port systems in advanced port communities both locally and internationally through the use of a single communication platform (Single Window systems) for exchange of information between interconnected ports.

It should be noted once again that in order to implement, operate and develop the potential applications and capabilities of a Port Information System is essential as much as possible the detailed analysis of all the individual processes, the specificities and the information required in order to ensure the simultaneous coverage of user needs to communicate with each other and generally their need for fast, safe and troublefree services.

\section{ACKNOWLEDGMENTS}

All authors would like to thank the University of West Attica and specifically the Post Graduate Program of Studies (MSc) "New Technologies in Shipping and Transport", for the financial support provided to them to undertake this research project.

\section{REFERENCES}

[1] Srour F. J., Van Oosterhout M., Zuidwijk R., Van Baalen P. J.,Port Community System Implementation: Lessons Learned from International Scan, Conference Paper: January 2008

[2] Ollivier, P. (2011). Port Community Systems Benchmark Survey. World Port Conference, Busan

[3] Laudon K.,C., Laudon J.,P., (2011), Management Information Systems, Publisher: Kleidarithmos, Athens 
[4] Kolios S., Petsios S. K.,Stilios D., C., 2013, Port Information Systems: Modern Trends and Prospects, Ediposis Publications

[5] Adriatic Port Community, http://www.apcwindow.eu/el

[6] Van Baalen, P., R. Zuidwijk, M. van Oosterhout, J. van Nunen (2007), Interorganizational Information Systems in Port Communities and Supply Chains: Continuing the success of containerized transport supply chains. Now Publishers, forthcoming.

[7] Venkatraman, N., "IT-Induced Business Reconfiguration," in Scott-Morton, M. S., The Corporation of the 1990s - Information Technology and Organizational Transformation, New York, NY: Oxford University Press, 1991.

[8] Carlan., Sys C., Vanelslander T ,How port community systems can contribute to port competitiveness: Developing a cost-benefit framework,.., Research in Transportation Business \& Management 19 (2016) pp. $51-64$

[9] UNCTAD, 2012, "Review of Maritime Transport", United Nations Publications
[10] Ioannidou E., 2010, Study and management of composite performance measurement indicators in Public Administration services (Governmental KPI's), University of the Aegean

[11] European Port Community System Association - MEDPCS Project, http://med-pcs.eu/project

[12] Tsamboulas D., Ballis A.,Port Community Systems: Requirements, Functionalities And Implementation Compilations, 13th World Conference on Transport Research,15-18 July 2013

[13] Vitsounis T., "Key Performance Indicators and Balanced Scorecard in Ports", Masport Seminar: Automation and Simulation Methodologies for the Evaluation and Improvement of Port Container Terminals, 2011.

[14] Mano P., Särkijärvi J., Katsoulakos T., Bojkova V.,2011, "Guide to Best Practice PromotionalL Activity Operational Key Performance Indicators, Grant Agreement No. TREN/FP7/TR/218621/"PROPS"

[15] Ports of Mediterranean, http://www.medcruise.com/

[16] Adriatic Sea Region, https://en.wikipedia.org/wiki/Adriatic_Sea 